\title{
Testing the Effect of Soil Heterogeneity on Arbuscular Mycorrhiza Fungi (AMF) Contribution to Plant Productivity
}

\author{
Samuel Ayesu*, Grace Gyabaah* \\ Resource Management Support Centre, Forestry Commission, Kumasi, Ghana \\ Email: samuelayesu@yahoo.com, ${ }^{*}$ sayesu.rmsc@fcghana.org
}

Received 4 January 2014; revised 4 February 2014; accepted 16 February 2014

Copyright (C) 2014 by authors and Scientific Research Publishing Inc.

This work is licensed under the Creative Commons Attribution International License (CC BY). http://creativecommons.org/licenses/by/4.0/

\section{c) (i) Open Access}

\begin{abstract}
Most natural soils are heterogeneous and nutrient availability and soil structure change greatly over small distances. It is still unclear whether AMF are advantageous for plants under such heterogeneous soil conditions. The objective of this study was to determine whether diverse AMF community support host plant community productivity in heterogeneous soil. It was also tested whether soil heterogeneity affects plant productivity. This was carried out in a greenhouse experiment made up of two factors: soil heterogeneity and AMF richness. Soil heterogeneity was simulated by mixing three soil types (sand, field soil and organic soil) together (homogenous soil (HM)), mixing them partly (semi homogenous $(\mathrm{SH})$ ) or keeping the three soil types separate in three compartments within one pot (heterogeneous (HT)). AMF richness was simulated by adding no AMF, one of four different AMF species separately, or all four different AMF together. The pots were planted with a mixture of Trifolium pratense and Lolium multiflorum. There was no effect of soil heterogeneity on total plant biomass. However, the biomass of the individual plant species was greatly affected by soil heterogeneity with Lolium being the most abundant in the heterogeneous soil and Trifolium being the most abundant in the homogenous soil. Total plant biomass did not increase with AMF richness. Moreover, opposite to the hypothesis, AMF richness was not beneficial for plant productivity in a heterogenous soil environment. However, there were significant differences in plant biomass with different AMF treatments in the SH and HT treatment indicating that effects of AMF on plant productivity are influenced by soil type. These effects on yield and AMF reflect a combination of local responses to growing conditions. The results show that AMF influence on plant yield may not always be positive but is strongly dependent on ecological elasticity and environmental condition.
\end{abstract}

\footnotetext{
${ }^{*}$ Corresponding authors.
}

How to cite this paper: Ayesu, S. and Gyabaah, G. (2014) Testing the Effect of Soil Heterogeneity on Arbuscular Mycorrhiza Fungi (AMF) Contribution to Plant Productivity. Open Journal of Ecology, 4, 299-310. 


\section{Keywords}

\section{Homogeneous, Heterogeneous, Arbuscular Mycorrhiza Fungi, Symbiosis, Clover, Grass}

\section{Introduction}

Symbiotic associations between plants and Arbuscular Mycorrhizal Fungi (AMF) are ubiquitous in many herbaceous plant communities and can have large effects on these communities and ecosystem processes. AM fungi belong to the phyla Glomeromycota with three families Glomeraceae, Acaulosporaceae and Gigasporaceae. About $80 \%$ of terrestrial plants form symbiotic association with AMF [1] [2]. Arbuscular mycorrhizal fungi are abundant in grassland, savannah and tropical forests and associate with many grasses, herbs, tropical trees and shrubs [3]. It is estimated that $84 \%$ of all grass species form AM associations [4]. Several studies have reported that AM fungi enhance plant productivity in grassland, and up to two-fold increases have been found [1]. In natural ecosystems, it has been demonstrated that plants obtain up to $80 \%$ of their requirement for nitrogen and up to $90 \%$ of phosphorus from mycorrhizal fungi [5]. Mycorrhizal fungi also provide resistance to stress, drought and in some cases to soil pathogens [6]. The impact of AMF has not always been positive as others studies found that AM fungi alter the distribution of nutrients amongst co-existing grassland species without altering total plant productivity [6]. The above evidence suggests that AMF are crucial for the functioning of terrestrial ecosystems and their diversity is decisive for both plant community structure and ecosystem productivity [7].

Few studies have been devoted to understanding the occurrence of specific AMF species to soil indirectly through physical and chemical characteristics such as soil texture, organic matter content and nutrient contents, in particular to the availability of phosphorus [8]-[11] and direct comparison of different soils [12].

Plant-fungi symbioses operate in highly heterogeneous space and time in natural environments. In nature soils are very heterogeneous, often with large changes in nutrient availability and soil structure over small distances. Also, the soil profile is made up of various zones or horizons and these provide different habitats for plant roots and soil microbes. Recent research has shown that spatial heterogeneity is essential in determining placement and growth of leaves and roots, the growth of whole plant, intensity of inter-plant competition, as well as the yield and structure of plant populations [13]-[17]. Other experimental evidences suggest that reduced soil complexity and increasing homogenization from agricultural activities such as tillage/ploughing and fertilisation have negative impact on AMF diversity and species richness [6] [18] [19]. These features may serve as filters for the selection of more adapted species of AMF that could persist in certain environments. Manipulative experiments however, with AMF in heterogeneous soil environment have been poorly explored.

Until recently, most knowledge about the interaction between AMF and plant growth has been based on experiments conducted under spatially homogeneous conditions [20]. Clover-grass communities are widely distributed in agriculture, especially because clover can enhance soil fertility due to its capacity to fix atmospheric nitrogen in symbiosis with nitrogen fixing rhizobia bacteria. Moreover, grasses and clover also represent important functional plant groups that are important in most agricultural settings known to enhance soil properties and AMF improving yields [21]. The objective of this study was to determine whether heterogeneous soil environment influenced AMF contribution to productivity of clover-grass communities. The hypothesis for the experiment:

1) Heterogeneous soil environment enhances plant productivity;

2) AMF and AMF richness enhance productivity;

3) Soil heterogeneity influences AMF contribution to aboveground productivity.

\section{Methodology}

\subsection{Soil and Inoculant Preparation}

A greenhouse experiment with three different soil materials (field soil, sand, and organic matter) was used. Field soil was collected from a long-term grassland field harbouring native Lolium and Trifolium spp. located at the Agroscope Reckenholz Research station in Zürich, Switzerland (047 $42^{\prime} 74^{\prime \prime N}$, 008 51'78"E). Collected field soil was then sieved through a $5 \mathrm{~mm}$ mesh in order to remove large stones and root fragments. Sand and Organic soil were obtained from Agroscope, Zurich to sterilise them, soils were then autoclaved at $120^{\circ} \mathrm{C}$ for 80 minutes and 
kept for 2 weeks before use. Soil sterilization of organic matter strongly enhances nutrient availability and therefore the organic matter was washed with distilled water to reduce the effect of nutrient loading AMF colonisation. A total of 126 litres of each experimental soil substrate was used. Three soil classes; homogeneous (HM), semi-homogeneous (SH) and heterogeneous (HT) were prepared from a combination of the sterilized sand, field soil and organic material (see Table 1).

All the three soil classes had equal amounts of $(1 \mathrm{~L})$ each of the substrates. Within each pot, each soil class was made up of three compartments (Figure 1 and Figure 2). These compartments were not treated as split plots but were connected to each other. Soil heterogeneity was simulated by mixing three soil types (sand, field soil and organic soil) together (homogenous soil (HM), mixing them partly (semi homogenous (SH) or keeping the three soil types separate in three compartments within one pot (heterogeneous (HT). AMF richness was simulated by adding no AMF, one of four different AMF species separate, or all four different AMF together (see Table 1). The pots were then planted with a mixture of Trifolium pratense and Lolium multiflorum. Samples of each soil mixture were taken after autoclaving for soil chemical analysis.

Table 1. Preparation and components of the soil class used for the experiment. The percentage of each primary soil material represents one liter of soil per compartment. In the homogeneous the sand, soil and organic were completely mixed in each compartment. The semi homogeneous was partly mixed with each soil dominating each of the compartment. The substrates heterogeneous for each compartment was completely partitioned. See Figure 2 for arrangement of compartments.

\begin{tabular}{ccccccccccc}
\hline \multirow{2}{*}{ Compartment } & \multicolumn{3}{c}{ Homogeneous } & \multicolumn{3}{c}{ Semi Homogeneous } & \multicolumn{2}{c}{ Heterogeneous } \\
\cline { 2 - 10 } & Sand & Soil & Organic & Sand & Soil & Organic & Sand & Soil & Organic \\
\hline A & $33 \%$ & $33 \%$ & $33 \%$ & $50 \%$ & $25 \%$ & $25 \%$ & $100 \%$ & 0 & 0 \\
B & $33 \%$ & $33 \%$ & $33 \%$ & $25 \%$ & $50 \%$ & $25 \%$ & 0 & $100 \%$ & 0 \\
C & $33 \%$ & $33 \%$ & $33 \%$ & $25 \%$ & $25 \%$ & $50 \%$ & 0 & 0 & $100 \%$ \\
\hline
\end{tabular}

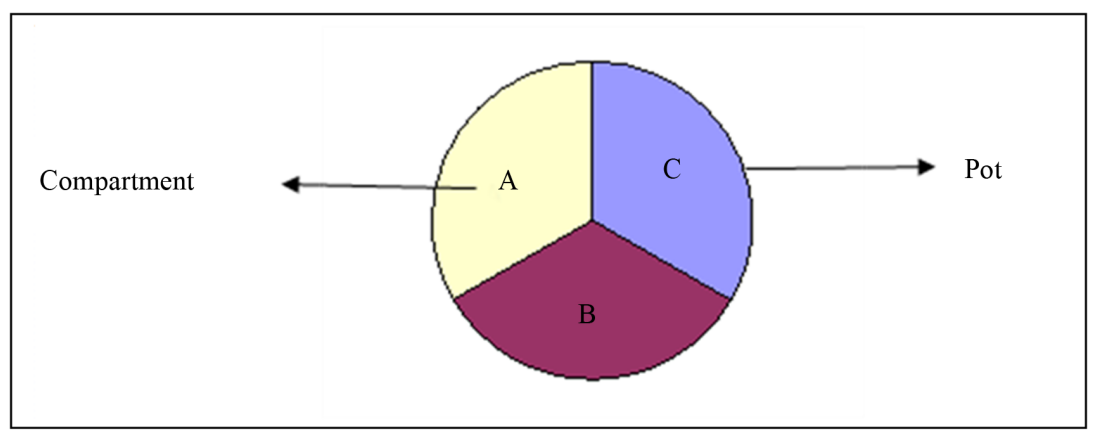

Figure 1. The arrangement of substrate compartment within each experimental pot for each soil class. A, B and C represent the compartments within a pot. The compartments were of equal size.

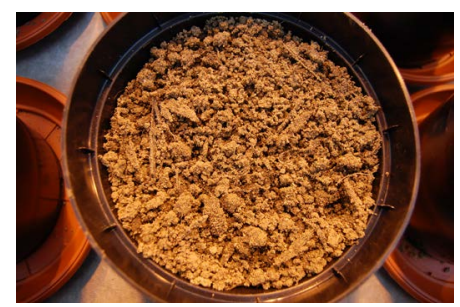

Homogeneous soil

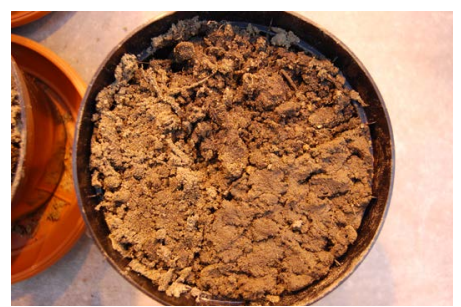

Semi homogeneous soil

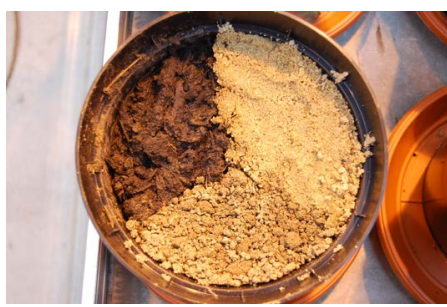

Heterogenous soil

Figure 2. The different soil classes used soil substrate for the experiment. These were Homogeneous soil Semi homogeneous soil and heterogenous soil. These were made of a mixture of three different soil types (field soil, sand and organic). For detail see Table 1. 
Four different AMF species were used for the experiment and these were Glomus intraradices (BEG 21, see [6] for description), G. mosseae (isolate JJ964, [22]), G. claroideum (isolate JJ132, [22]) and Diversispora celata (FACE 234, [23]). These fungi were cultured on Plantago lanceloata for 5 to 6 months in sand mixed with $10 \%-20 \%$ field soil, receiving $20 \mathrm{ml}$ Hoagland's nutrient solution [24] with $0.25 \mathrm{KH}_{2} \mathrm{PO}_{4}$ every two weeks and watered to maintain $20 \%$ soil moisture by weight. A control inoculum (no AMF) was prepared in the same way as the four AMF inoculants. Glomus claroideum, G. intraradices, G. mosseae and D. celata inoculants were observed colonizing $12.5 \%, 84 \%, 32.5 \%$ and $1 \%$ of $P$. lanceloata roots with 34.3, 22, 41.2 and 122 spores per $\mathrm{cm}^{3}$ of soil respectively. No AMF spores or colonization of roots was observed in the control inoculum. A non mycorrhizal treatment, treatments of four individual AMF species and a combination of all four AMF was prepared, adding up to a total of six AMF treatments (Table 2) with seven replicate each for 3 soil classes totalling 126 pots.

Single AMF inoculated pots received $50 \mathrm{ml}$ of inoculum, containing substrate and root fragments, of each of the four AMF. Treatments co-inoculated with all four AMF species received $12.5 \mathrm{ml}$ of roots and substrate of each AMF inoculum; totalling $50 \mathrm{ml}$ of inoculum. All AMF treatments were inoculated in $3 \mathrm{~L}$ pots containing $1.9 \mathrm{~kg}$ (dry weight) of each of the three soil classes (homogeneous, semi homogeneous and heterogeneous) and the inoculums were thoroughly mixed with the soil substrate within each pot (Table 2).

\subsection{Seedling Preparation and Planting}

Seedlings of Trifolium pratense and Lolium multiflorum were prepared by surface sterilizing seeds by agitating seeds in $1.25 \%$ sodium hypochlorite (diluted household bleach) for 10 minutes followed by a thorough rinse in $\mathrm{dH}_{2} \mathrm{O}$ and subsequently placed on $1.5 \%$ water agar in a petri dish for 2 - 4 days. These plants species were selected because known to be colonised by AMF and secondly they widely distributed in grassland sites and represent important functional plant groups (grass and legume). Germinated seeds were then planted evenly spaced with 9 seedlings for each species per experimental pots (3 per each third of the pot that contained different soil substrate mix). Pots were covered with cellophane for one week to allow seedlings to establish. Seedlings that did not survive were replaced up to two weeks post initial planting. A microbial wash was added to each pot post planting in order to standardize the microbial community within each pot with a natural grass-clover soil microbial community. The microbial wash was created by using $1 \mathrm{~L}$ of the un-autoclaved field soil by wet sieving through a series of sieves with the smallest being $10 \mu \mathrm{m}$ with $8 \mathrm{~L}$ of $\mathrm{dH}_{2} \mathrm{O}$ per litre of soil. The experimental pots were randomly distributed within the greenhouse. The plants were maintained under a temperature of $25^{\circ} \mathrm{C}$ with a light regime of $16 \mathrm{~h}$ day light maintained above $300 \mathrm{~W} / \mathrm{m}^{2}$ by $400-\mathrm{W}$ high-pressure sodium lamps. Watering was done four times per week to maintain a $30 \%$ soil moisture by weight.

\subsection{Harvest and Measurement}

After 12-week of growth after transplanting, shoot and root data was collected. Plant shoots were harvested at

Table 2. A matrix of the experimental design with soil classes and Arbuscular Mycorrhiza Fungi (AMF) inoculant treatments. The experimental set is made up of three soil treatments and six AMF treatment resulting in a total of 18 treatments. The numbers represent: $1=$ non mycorrhizal control, 2 to 5 refers to the individual AMF treatments and 6 stands for all the four AMF species combined in a treatment.

\begin{tabular}{cccc}
\hline & \multicolumn{2}{c}{ Soil class } \\
\hline AMF treatment & Homogeneous (HM) & Semi homogeneous (SH) & Heterogeneous (HT) \\
\hline 1 & Non AMF control & Non AMF control & Non AMF control \\
2 & G. mosseae & G. mosseae & G. mosseae \\
4 & G. intraradices & G. intraradices & G. intraradices \\
5 & G. claroideum & G. claroideum & G. claroideum \\
6 & D. celata & D. celata & D. celata \\
\hline
\end{tabular}


the soil surface and oven dried at $80^{\circ} \mathrm{C}$ and their biomass recorded to the nearest tenth of a mg. Plant roots were extracted compartment by compartment as per soil class and washed free of soil, and frozen at $-20^{\circ} \mathrm{C}$ until they could be processed further. Frozen roots were thawed, cut into small $(1-2 \mathrm{~cm})$ fragments to examine extent of AMF root colonization. To determine the level of colonization of AMF inoculated within each compartment within a pot, a random sample of approximately $1-2 \mathrm{~g}$ of fresh root was fixed in $50 \%$ ethanol, cleared with $10 \%$ $\mathrm{KOH}$ in an $80^{\circ} \mathrm{C}$ water bath for 45 minutes then stained with $5 \%$ pen ink vinegar [25] for 10 min in an $80^{\circ} \mathrm{C}$ water bath. Random sub-sampling of the cleared and stained roots was then mounted on glass slides with $50 \%$ glycerine under a cover slip. Roots were then assessed for percentage of mycorrhizal root length colonization based on absence or presence of AMF structures using the intersect method outlined by [26] for 100 intersects.

\subsection{Experimental Design and Data Analysis}

The experiment was set up as a factorial design made up of two factors: soil class and AMF treatment. The soil class was made up of three levels while the AMF treatment was made of six categories (see Table 1). A two-way analysis of variance (ANOVA) was used to examine the effect of soil class and AMF, and their interaction, on biomass production in T. pratense and L. multiflorum. Where a significant difference was observed, a posthoc test by Tukey HSD was used to determine significant differences among each of the AMF and soil class factor levels. In order to determine the variation among the three compartments and the effect of AMF in each compartment, a nested ANOVA was done for each soil class seperately with the factor error term for compartments nested within pots. It was also used to test effect of compartment and AMF on plant biomass in different soil types. One-way analysis of variance was used to determine the effect of AMF in different soil classes on plant biomass in the different soil classes. Where a significant difference was observed, a posthoc test with tukey HSD was used determine which of the individual treatments were significantly different. A Spearman correlation analysis was done between $T$. pratense and L. multiflorum biomass to assess inferences regarding plantplant competition. One of the control pots was contaminated by mycorhizal infection in the roots and was therefore removed from all analyses. Treatments levels were considered to differ significantly with a type I error greater than 0.05. All statistics were done using the R-statistical package (version 2.11.1).

\section{Results}

This section presents the results and trends recorded during the experiment.

\subsection{AMF Root Colonisation}

The percentage of root colonized by mycorrhizal fungi for the five AMF treatment were Glomus intraradices (51\%), Glomus claroideum (46.7\%), Glomus mosseae (28.3\%), Diverspora celata (7.57\%) and the combined AMF treatment (49.3\%). Glomus intraradices produced highest level of colonization of Trifolium pratense and Lolium multiflorum roots whiles the lowest was observed in D. celata. For the soil treatments, percent colonisation was homogeneous (34.4\%), semi homogeneous (37.7\%) and heterogeneous (32\%).

\subsection{Aboveground Biomass}

\subsubsection{Effect of Soil Heterogeneity}

The combined aboveground biomass for Trifolium pratense and Lolium multiflorum was highest in homogeneous soil (Figure 3). Two way analysis of variance showed significant effect of soil treatment on productivity of Trifolium pratense and Lolium multiflorum $(\mathrm{F}=4.57, \mathrm{P}=0.01$ ). L. multiflorum grew significantly (Figure 3; $\mathrm{F}$ $=95.16, \mathrm{P}=2 \mathrm{e}-16$ ) greater in the heterogeneous soil, while the T. pratense (Figure 4; $\mathrm{F}=68.2, \mathrm{P}=2 \mathrm{e}-16$ ) biomass was least in the heterogeneous soil. In the homogeneous and semi homogeneous, the biomass of $T$. pratense and L. multiflorum were almost the same.

\subsubsection{Effect of AMF and AMF Species Richness}

There was no effect of AMF and AMF richness on aboveground biomass of T. pratense and L. multiflorum (Figure 4, $\mathrm{F}=1.93, \mathrm{P}=0.09$ ). At the individual plant species level, there was no mycorrhizal effect on plant shoot biomass for $T$. pratense (Figure 6, F = 2.1, P = 0.07) but there was significant effect in the case of $L$. mul- 


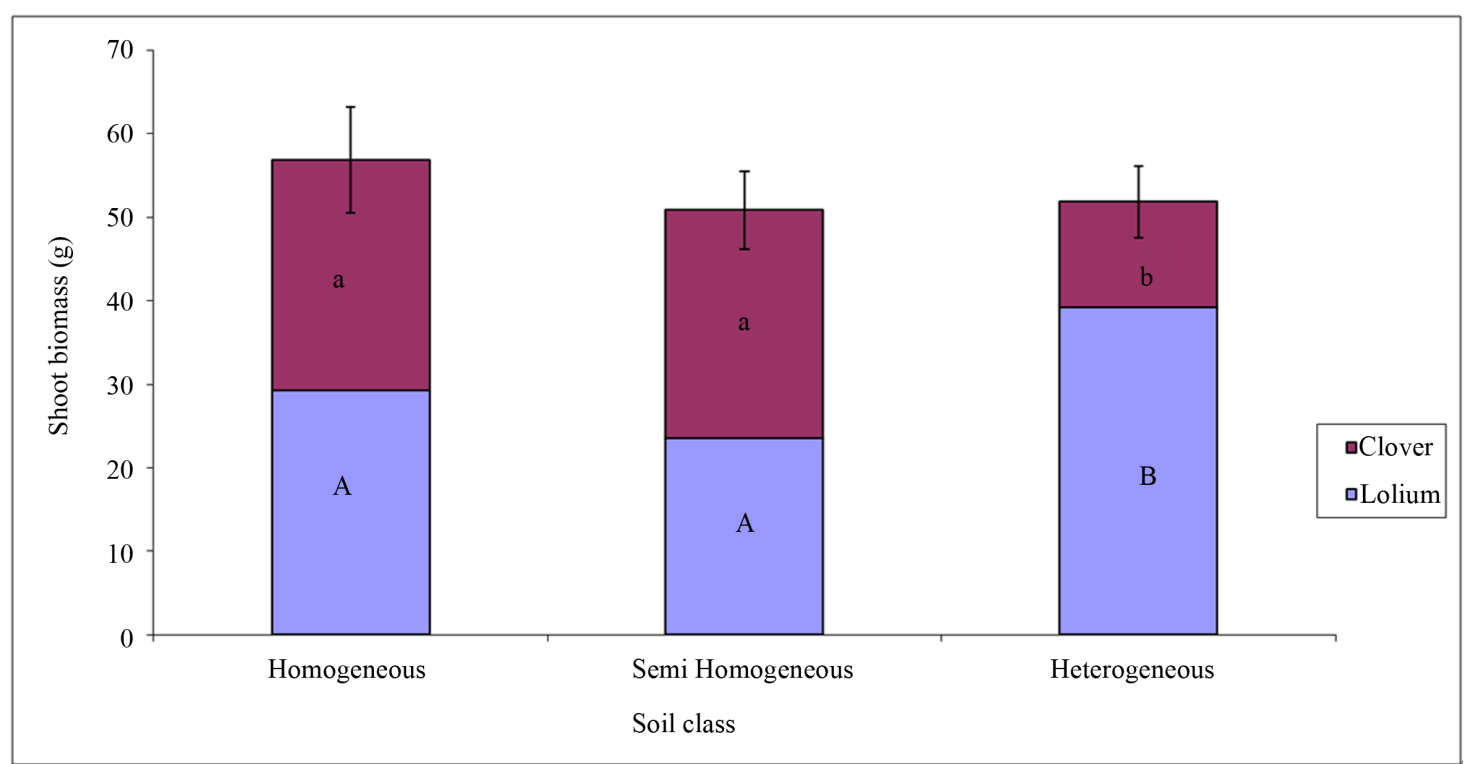

Figure 3. Mean shoot biomass (with standad error) or Trifolium pretense and Lolium multiflorum in three different soil classes. The letters (a, b, A and B) represent treatments that are significantly different.

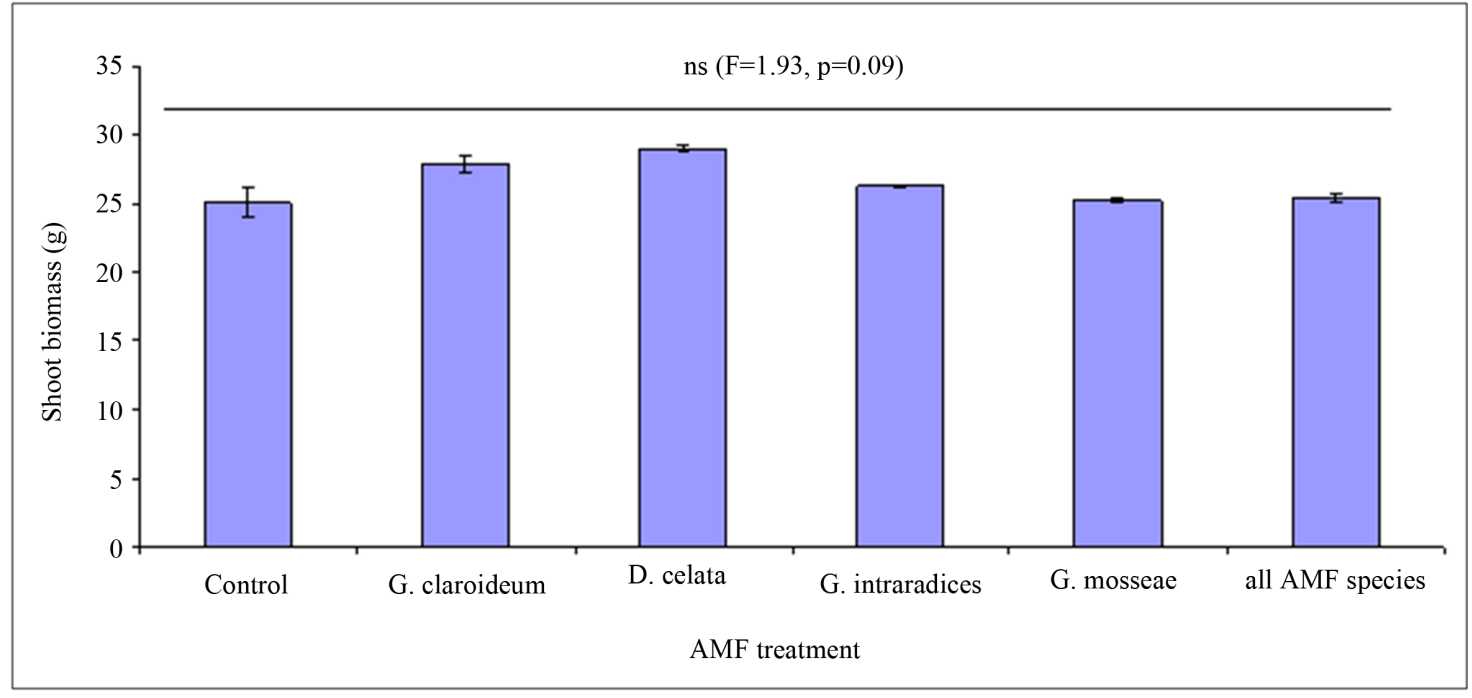

Figure 4. Effect of Arbuscular Mycorrhiza Fungi (AMF) on shoot biomass (with standard errors) of Trifoliium pretense and Lolium multiflorum.

tiflorum (Figure 5: $\mathrm{F}=3.12, \mathrm{P}=0.01$ ). However, there was a positive effect of AMF plant productivity although this was marginal compared to non mycorrhizal control. The highest shoot biomass was observed in Diversispora celata treatment followed by G. claroideum (Figure 4). The lowest biomass was recorded in the non mycorrhizal control. Among the AMF species, the effect of AMF richness on plant productivity was low, only being greater than the $G$. mosseae.

\subsubsection{Effect of Heterogeneous Environment on AMF}

The ANOVA showed that soil class by AMF interaction had a significant influence on the combined productivity of $T$. pratense and L. multiflorum $(\mathrm{F}=2.32, \mathrm{P}=0.02$ ). This was the case for $L$. multiflorum biomass (Figure 5: $\mathrm{F}=3.12, \mathrm{P}=0.01$ ) but no effect on productivity of $T$. pratense (Figure $6, \mathrm{~F}=2.1, \mathrm{P}=0.07$ ). The AMF richness treatment performed poorly compared to the individual treatment across the three soil classes to both $L$. multiflorum and T. pratense productivity. 


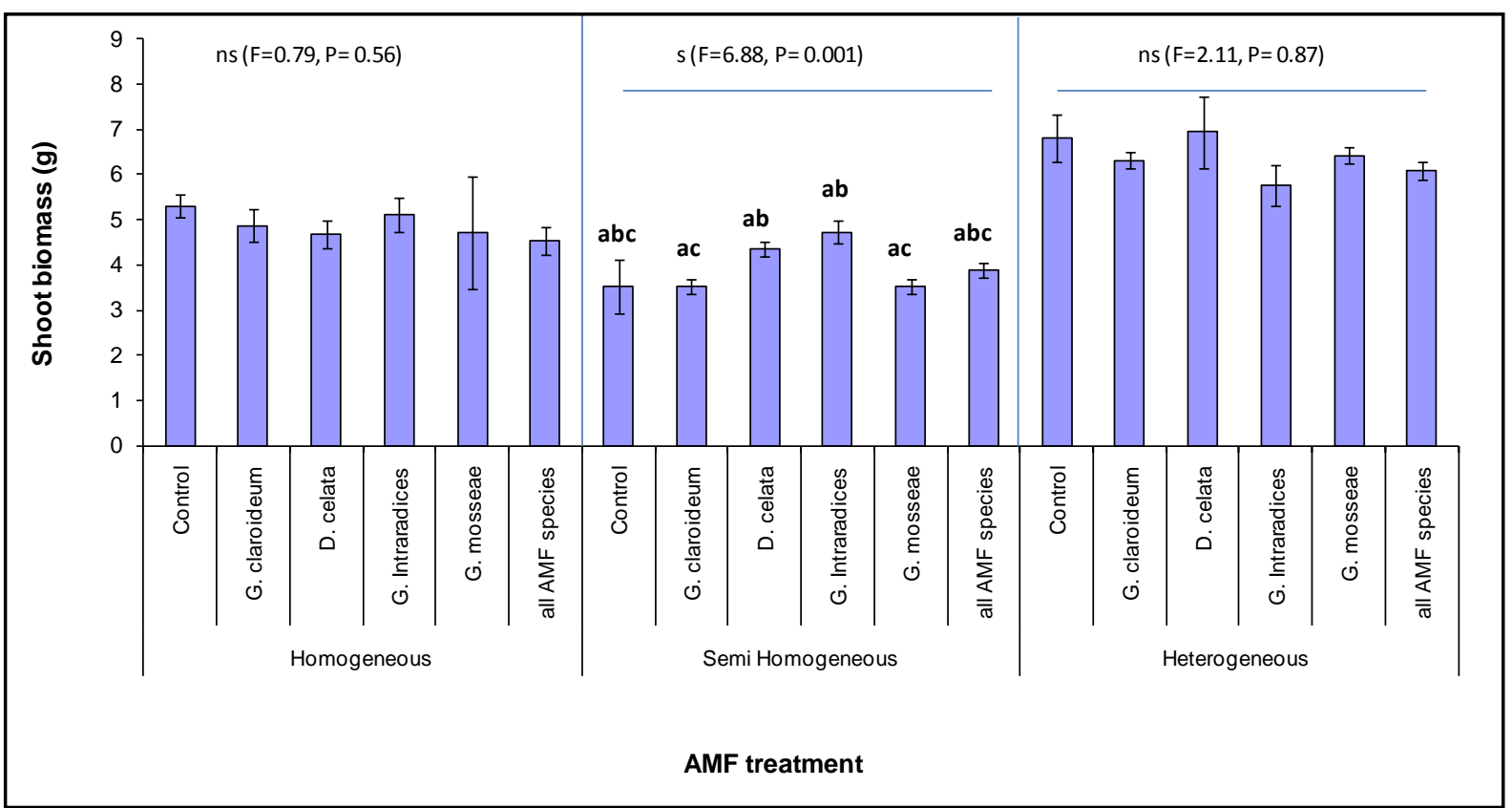

Figure 5. Shoot biomass of Lolium multiflorum (with standard error) planted with different Arbuscular Mycorhizal Fungi (AMF) species in three different soil classes. The letters ( $a, b$ and c) represent treatments that are significantly different.

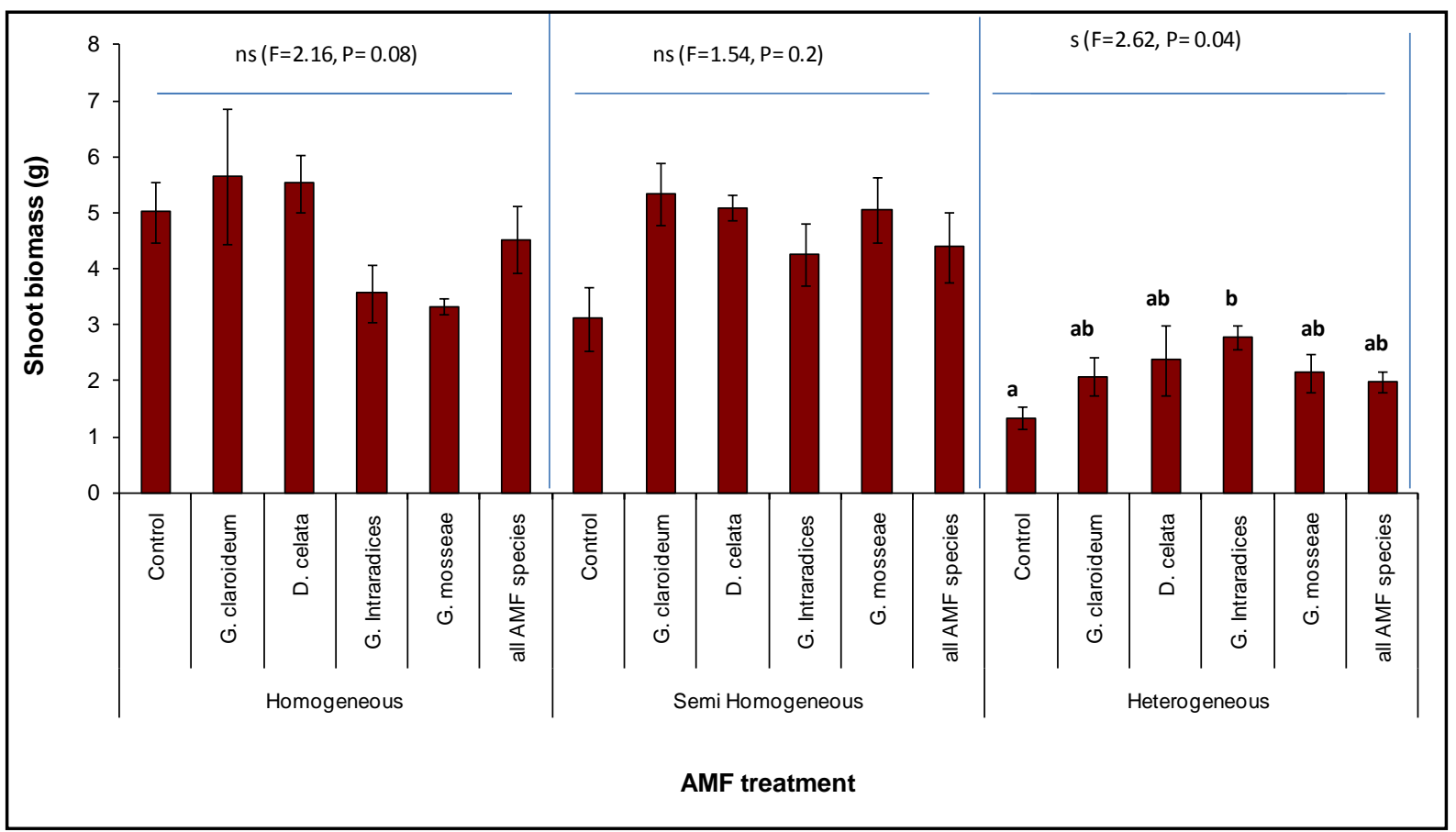

Figure 6. Shoot biomass of Trifolium pratense (with standard error) planted with different. Arbuscular Mycorhizal Fungi (AMF) treatment in three different soil class. The letters (a and b) represent treatments that significantly different.

\section{1) Effect on L. multiflorum}

Further analysis showed that the AMF effect on L. multiflorum was only significantly different among AMF treatments in the Semi homogeneous $(F=6.88, P=0.0001)$ and not in the heterogeneous or homogeneous soil (Figure 5). In the homogeneous soil, all the AMF treatments resulted in lower L. multiflorum biomass than the non-mycorrhizal control. A similar effect was also observed in the heterogeneous soil, but in this case $D$. celata 
was greater than the non-mycorrhizal treatment. In contrast, all mycorhizal treatments were higher than the nonmycorrhizal control in the case of SH. In the semi-homogeneous soil, G. intraradices recorded the highest value followed by $D$. celata. Lower values were measured in the other individual species and also in the combined AMF treatment. The posthoc test with Tukey HSD revealed significant differences between $G$. mosseae and $G$. intraradices, G. mosseae and D. celata, as well as between G. intraradices and G. claroideum. The AMF richness treatment performed poorly compared to the individual treatment across the three soil classes as in the $L$. multiflorum.

\section{2) Effect on $T$. pratense}

Although there was no effect on T. pratense, an individual analysis of the three soil treatments showed significant differences in AMF effect on aboveground biomass in the Heterogeneous soil (Figure 6, $\mathrm{F}=2.16, \mathrm{P}=$ 0.04) although productivity was comparatively lower. Also the control treatment was consistently lower than the mycorrhizal treatments in the HT and SH (Figure 6). A post-hoc test with Tukey HSD showed only G. intraradices to be significant different from the control (Figure 6). Comparison of AMF effect in the three soil treatments, showed that G. claroideum exerted the strongest effect in homogeneous and semi-homogeneous while in the heterogeneous soil it was G. intraradices. Compared to the control, Glomus claroideum and $D$. celata inoculated treatments showed dominant effect in the homogeneous, whereas in the SH and HT all the AMF species recorded means greater than the non-mycorrhizal control.

\subsection{Soil Physical and Chemical Analysis}

Selected soil chemical parameters ( $\mathrm{pH}$, available phosphorus $(\mathrm{P})$, potassium $(\mathrm{K})$, magnesium $(\mathrm{Mg})$ \& Calcium (Ca) content) for each soil class are presented in Table 2. They were measured in the laboratory of Agroscope Reckenholz-Tanikon Research station, Zürich, according to standard methods with ammonium acid-extraction (AAE10) approach. The $\mathrm{pH}$ of the soils ranged between 6.5 and 8 (Table 3). The organic soil was characterised by high phosphorus level. This was about four times higher than the value of the organic dominated in the Semi homogeneous soil (Table 3). The lowest phosphorus level was recorded in the field soil.

Table 3. Soil physical and chemical parameters of different soil classes. The soil type represents the individual compartments within a pot across the soil gradient. For the Semi-homogeneous, the organic dominated represent (OD—50\%, FD— $25 \%$ \& SD-25\%), Field soil dominated (FD-50\%, OD-25\% \& SD-25\%) and Sand dominated (SD-50\%, OD-25\% \& FD-25\%). The heterogeneous is made of the pure individual soil materials. Available phosphorus (P), potassium (K), magnesium (Mg) \& Calcium (Ca) content were extracted with ammonium acid-extraction (AAE10), $\mathrm{CO}_{2}$ and $\mathrm{CaCl}_{2}$.

\begin{tabular}{|c|c|c|c|c|c|c|c|c|c|c|}
\hline Soil Class & $\begin{array}{c}\text { Soil } \\
\text { Material }\end{array}$ & $\mathrm{pH} \mathrm{H} \mathrm{H}_{2} \mathrm{O}$ & $\begin{array}{c}\text { Kalkzust } \pm \\
\text { bzw. } \%\end{array}$ & $\begin{array}{l}\text { P-Test } \\
\left(\mathrm{CO}_{2}\right)\end{array}$ & $\begin{array}{c}\text { K-Test } \\
\left(\mathrm{CO}_{2}\right)\end{array}$ & $\begin{array}{l}\text { Mg-Test } \\
\left(\mathrm{CaCl}_{2}\right)\end{array}$ & $\begin{array}{l}\mathrm{P} \mathrm{mg} / \mathrm{kg} \\
\text { (AAE10) }\end{array}$ & $\begin{array}{l}\mathrm{K} \mathrm{mg} / \mathrm{kg} \\
\text { (AAE10) }\end{array}$ & $\begin{array}{l}\mathrm{Mg} \mathrm{mg} / \mathrm{kg} \\
\text { (AAE10) }\end{array}$ & $\begin{array}{l}\text { Ca mg/kg } \\
\text { (AAE10) }\end{array}$ \\
\hline Homogeneous & & 7.2 & + & 73.6 & 30.2 & 16.2 & 117.2 & 495.9 & 305.7 & 9008 \\
\hline \multirow[t]{3}{*}{ Semi-homogeneous } & $\begin{array}{l}\text { Organic } \\
\text { dominated } \\
\text { (OD) }\end{array}$ & 7.7 & + & 62.0 & 65.8 & 23.0 & 208.5 & 935.9 & 431.8 & 10,576 \\
\hline & $\begin{array}{l}\text { Field soil } \\
\text { dominated } \\
\text { (FD) }\end{array}$ & 7.2 & + & 28.9 & 22.0 & 13.5 & 105.6 & 384.7 & 252.9 & 6995 \\
\hline & $\begin{array}{c}\text { Sand } \\
\text { dominated } \\
\text { (SD) }\end{array}$ & 7.4 & + & 37.3 & 26.0 & 9.2 & 98.7 & 358.5 & 187.2 & 8137 \\
\hline \multirow[t]{3}{*}{ Heterogeneous } & Organic (O) & 8 & + & 42.9 & 47.5 & 58.5 & 1152.3 & 6819.2 & 2186.8 & 25,150 \\
\hline & Field soil (F) & 6.5 & - & 1.9 & 0.8 & 12.4 & 6.4 & 53.0 & 146.8 & 1513 \\
\hline & Sand (S) & 7.0 & + & 8.4 & 0.3 & 1.2 & 48.9 & 15.7 & 61.7 & 6692 \\
\hline
\end{tabular}




\section{Discussion}

\subsection{Heterogeneous Soil and Plant Productivity}

Previous studies have demonstrated large differences in growth benefit obtained by plants in heterogeneous environment [12] [14] [18] [20] [27]-[30]. Some studies found that plants benefit when grown in a heterogeneous soil [20] [31] while other studies found that plant do best when grown in a homogenous soil type [31]-[34]. Although there was no effect of soil heterogeneity on overall plant biomass, both investigated plant species responded very differently to soil heterogeneity. $L$. multiflorum benefit in the heterogeneous soil while $T$. pratense performed best in the homogeneous. Similar observations have been made in experiments with Trifolium repens [14] and Glechoma hederacea [20]. Several studies have also shown that when patch scale is very small, growth can even be poorer than in homogeneous conditions with the same amount of nutrients [20] [32] [33] and when conditions fluctuate rapidly through time [35] such as nutrient dynamics and soil moisture. [20] found growth benefit in heterogeneous soil to be higher than homogeneous condition when patches are large with nutrient contrast of 90:10.

Ample evidence suggests plant productivity is more strongly influenced by heterogeneous rather than homogeneous resource distribution even if the total resource supply remains the same [36]. The effect of heterogeneous environment may sometimes only be evident in the variation of aboveground biomass of plant species and not necessary the total biomass. For instance in both the L. multiflorum and T. pratense there was significant variation in shoot biomass in the heterogeneous soil which was not the case in the homogeneous and Semi homogeneous. Such differences are typical of a natural ecosystem with varying spatial soil properties and efficiency of nutrient uptake by plants. Moreover, the negative correlation $\left(-0.61, \mathrm{R}^{2}=0.33, \mathrm{P}=3.28 \mathrm{e}-12\right)$ observed between $T$. pratense and $L$. multiflorum biomass suggesting possible competition among the plant species for soil resources. Competition for soil resources can alter the biomass of co-existing species of plants leading to higher biomass in the plant that is better adapted to the conditions under which the plant community is exposed. The results suggest $L$. multiflorum to be better adapted to heterogeneous soil than the $T$. pratense. This means that not all heterogeneous environments enhance plant performance equally among species. Responses to heterogeneity and its contribution to plant productivity seem to be contingent on species and soil type as well as other edaphic factors.

\subsection{Soil Moisture and Nutrient Uptake}

Patchy nutrient distribution of $\mathrm{N}$ and $\mathrm{P}$ are influenced by dry conditions [2]. The water holding capacity of the different soil treatments used in this study may have influenced plant productivity and microbial activity. The Homogeneous and Semi homogeneous were visually observed to dry more slowly than the Heterogeneous with the exception of the field soil compartment. Water films are important media for uptake and transport of labile nutrients by plant roots [2]. This may have provided the $T$. pratense and $L$. multiflorum equal opportunity and time for establishment and growth in the Semi homogeneous. This probably also accounts for the even growth between plant species in the Homogeneous and Semi homogeneous, and an unequal biomass in the Heterogeneous soil by both plant species. These results indicate increasing homogenization of soils may cause shifts in the natural variation by altering the competitive ability of different co-existing species. This may consequently lead to changes in plant community structure and alter the natural balance in ecosystem function and stability.

\subsection{Impact of Heterogeneity on AMF Performance}

Generally, there was no effect of AMF and AMF richness on aboveground biomass, although the mycorrhizal treatments had biomass that were higher than the non mycorrhiza control. In most cases the individual AMF treatments performed better than the diversity treatment. G. claroideum and D. celata, had high effect on plant productivity with $G$. intraradices showing intermediate effect across all the three different soils. The overall mycorrhizal effect across the soils was generally negative in effect in the homogeneous soil than in the other soils. Significant differences among AMF treatments were only observed in the Semi homogeneous soil ( $L$. multiflorum) and heterogeneous soil (T. pratense). This would indicate that although homogeneous soil may cause increase in plant biomass, it may results in the reduction of mycorrhiza effect as well as a shift in the co-existence of two commonly co-occurring AMF plant hosts. Such a situation may provide more competitive advantage to non-mycorrhizal species to the detriment of mycorrhizal dependant plant hosts. The even distribution of 
nutrient in the homogeneous soil may have consequently led to reduced importance of AMF as agents of nutrient cycling, thus reducing their effectiveness in nutrient uptake. This perhaps exerts a high cost in terms of carbon trade on treatments with mycorrhiza fungi. This observation is consistent with other studies that found intensively managed or disturbed (homogeneous) soil environment to reduce AMF diversity and function [12] [18] [30] [37]. This observation supports the hypothesis that heterogeneous environments may enhance AMF functioning.

Despite increasing the AMF effect with increasing heterogeneity, within the heterogeneous soil, fungal activity was not consistently positively improving plant biomass as was seen in the Semi homogeneous soil. Many of these results could be interpreted in terms of reduced signaling and transfer of resources between plants and fungi. For instance, a reduced allocation of nutrients to plant roots caused by AMF in high nutrient patches without a compensatory response by AMF in less fertile patches in the export of nutrients in the heterogeneous soil [14] [20] [30]. It therefore appears the impact of AMF diversity on plant productivity may not always be positive and is dependent on the nutrient status and other environmental variables.

\subsection{AMF Richness Mediation of Plant Productivity}

The low effect of AMF richness was contrary to what was expected and could possibly be due to antagonism among AMF species and high p levels at the initial stages of the experiment, especially in the organic dominated soils. The simultaneous requirement for carbon by mixed species AMF treatment from the host plant without compensatory import of P could result in a net cost to the host that may be higher than in the individual AMF in higher nutrient environment [38]-[40]. Moreover, the experiment was performed for short period (12 weeks) and effects of AMF and AMF richness may mostly become apparent in the long-term. It is anticipated that a 6 months to one year experiment could enhance AMF effect resulting from the depletion of nutrient over time. This observation supports previous studies that have shown that AMF are beneficial for plant productivity under nutrient poor soil conditions [1].

\section{Conclusion and Recommendations}

The findings of this study illustrate that 1 ) soil heterogeneity was not important for grass-clover community productivity, although the shoot biomass of individual plant species is dependent very much on soil heterogeneity, 2) AMF and AMF richness did not exert significant effect on plant productivity 3) AMF diversity does not always improve plant productivity in a heterogeneous soil environment, and finally 4) the impact of heterogeneous environment on the functioning of AMF richness is context dependent and is strongly influenced by the nutrient status of the patches. Given the wide distribution of both AMF and clover-ryegrass communities in both agricultural landuse and natural grassland ecosystems, in combination with the ubiquitous nature of heterogeneity in soil resource supply, such interactions are of key importance in explaining plant productivity. Since few studies have been conducted on AMF in heterogeneous soils, future studies could therefore look at the interplay of local and systemic scale along a different contrasting heterogeneous environment and nutrient levels to help understand the probable impact of AMF richness and function on plant community productivity. It will also be interesting to further explore the N/P dynamics at the beginning and end of such experiments since these elements are important determinant of AMF nutrient mediation in plant-fungi symbiosis in disturbed soils. Such information could be useful in designing agricultural and ecosystem management systems that generate stabilizing feedbacks between aboveground and belowground communities.

\section{Acknowledgements}

I am very grateful to TBA for financial support towards my Master programme, Dr Gerrard Driessen, Animal Ecology Department (Vrije Universiteit Amsterdam) and all who in diverse ways supported this research including reviewers of this paper.

\section{References}

[1] van der Heijden, M.G.A., Klironomos, J.N., Ursic, M., Moutoglis, P., Streitwolf-Engel, R., Boller, T., et al. (1998) Mycorrhizal Fungal Diversity Determines Plant Biodiversity, Ecosystem Variability and Productivity. Nature, 396, 69-72. http://dx.doi.org/10.1038/23932 
[2] Ryel, R.J. and Caldwell, M.M. (1998) Nutrient Acquisition from Soils with Patchy Nutrient Distribution as Assessed with Simulation Models. Ecology, 79, 2735-2744. http://dx.doi.org/10.1890/0012-9658(1998)079[2735:NAFSWP]2.0.CO;2

[3] Read, J. and Perez-Moreno, J. (2003) Mycorrhizas and Nutrient Cycling in Ecosystems-A Journey towards Relevance? New Phytologist, 157, 475-492. http://dx.doi.org/10.1046/j.1469-8137.2003.00704.x

[4] Eom, A., Hartnett, D.C. and Wilson, G.W.T. (2000) Host Plant Species Effects on Arbuscular Mycorrhizal Fungal Communities in Tallgrass Prairie. Oecologia, 122, 435-444. http://dx.doi.org/10.1007/s004420050050

[5] van der Heijden, M.G.A., Bardgett, R.D. and Nico, M.V.S. (2008) The Unseen Majority: Soil Microbes as Drivers of Plant Diversity and Productivity in Terrestrial Ecosystems.

[6] van der Heijden, M.G.A., Streitwolf-Engel, R., Riedl, R., Siegrist, S., Neudecker A., Ineichen K., et al. (2006b) The Mycorrhizal Contribution to Plant Productivity, Plant Nutrition and Soil Structure in Experimental Grassland. New Phytologist, 172, 739-752. http://dx.doi.org/10.1111/j.1469-8137.2006.01862.x

[7] Oehl, F., Sieverding, E., Ineichen, K., Mäder, P., Boller, T. and Wiemken, A. (2003) Impact of Land Use Intensity on the Species Diversity of Arbuscular Mycorrhizal Fungi in Agroecosystems of Central Europe. Applied and Environmental Microbiology, 69, 2816-2824. http://dx.doi.org/10.1128/AEM.69.5.2816-2824.2003

[8] Uhlmann, E., Görke, C., Petersen, A. and Oberwinkler, F. (2004) Arbuscular Mycorrhizae from Semiarid Regions of Namibia. Canadian Journal of Botany, 82, 645-653. http://dx.doi.org/10.1139/b04-039

[9] Landis, F.C., Gargas, A. and Givnish, T.J. (2004) Relationships among Arbuscular Mycorrhizal Fungi, Vascular Plants and Environmental Conditions in Oak Savannas. New Phytologist, 164, 493-504. http://dx.doi.org/10.1111/j.1469-8137.2004.01202.x

[10] Smith, S.E. and Read, D.J. (2008) Mycorrhizal SYMBIOSIS. 3rd Editon, Academic Press, London.

[11] Bashan, Y., Khaosaad, T., Salazar, B.G., Ocampo, J.A., Wiemken, A., Oehl, F. and Vierheilig, H. (2007) Mycorrhizal Characterization of the Boojum Tree, Fouquieria columnaris, an Endemic Ancient Tree from the Baja California Peninsula, Mexico. Trees, 21, 329-335.

[12] Oehl, E.L., Bogenrieder, A., Stahr, K., Bösch, R., van der Heijden, M., et al. (2010) Soil Type and Landuse Intensity Determine the Composition of Arbuscular Mycorrhizal Fungal Communities. Soil Biology and Biochemistry, 42, 724738. http://dx.doi.org/10.1016/j.soilbio.2010.01.006

[13] McGonigle, T.P. and Fitter, A.H. (1990) Ecological Specificity of VAM Associations. Mycological Research, 94, 120-122. http://dx.doi.org/10.1016/S0953-7562(09)81272-0

[14] Du, F.Yu, Alpert, P. and Dong, M. (2009) Arbuscular Mycorrhizal Fungi Reduce Effects of Physiological Integration in Trifolium repens. Annals of Botany, 104, 335-343. http://dx.doi.org/10.1093/aob/mcp130

[15] Fransen, B. and de Kroon, H. (2001) Long-Term Disadvantages of Selective Root Placement: Root Proliferation and Shoot Biomass of Two Perennial Grass Species in a 2-Year Experiment. Journal of Ecology, 89, 711-722. http://dx.doi.org/10.1046/j.0022-0477.2001.00589.x

[16] Facelli, E. and Facelli, J.M. (2002) Soil Phosphorus Heterogeneity and Mycorrhizal Symbiosis Regulate Plant IntraSpecific Competition and Size Distribution. Oecologia, 133, 54-61. http://dx.doi.org/10.1007/s00442-002-1022-5

[17] Wijesinghe, D.K., John, E.A. and Hutchings, M.J. (2005) Does Pattern of Soil Resource Heterogeneity Determine Plant Community Structure? An Experimental Investigation. Journal of Ecology, 93, 99-112. http://dx.doi.org/10.1111/j.0022-0477.2004.00934.x

[18] Jansa, J., Mozafar, A., Kuhn, G., Anken, T., Ruh, R., Sanders, I.R., et al. (2003) Soil Tillage Affects the Community Structure of Mycorrhizal Fungi in Maize Roots. Ecological Applications, 13, 1164-1176. http://dx.doi.org/10.1890/1051-0761(2003)13[1164:STATCS]2.0.CO;2

[19] Oehl, F., Sieverding, E., Ineichen, K., Ris, E.A., Boller, T. and Wiemken, A. (2005) Community Structure of Arbuscular Mycorrhizal Fungi at Different Soil Depths in Extensively and Intensively Managed Agroecosystems. New Phytologist, 165, 273-283. http://dx.doi.org/10.1111/j.1469-8137.2004.01235.x

[20] Hutchings, M.J. and Wijesinghe, D.K. (2008) Performance of a Clonal Species in Patchy Environments: Effects of Environmental Context on Yield at Local and Whole-Plant Scales. Evolutionary Ecology, 22, 313-324. http://dx.doi.org/10.1007/s10682-007-9178-4

[21] Nyfeler, D., Huguenin-Elie, O., Suter, M., Frossard, E., Connolly, J. and Lüscher, A. (2009) Strong Mixture Effects among Four Species in Fertilized Agricultural Grassland Led to Persistent and Consistent Transgressive Overyielding. Journal of Applied Ecology, 46, 683-691. http://dx.doi.org/10.1111/j.1365-2664.2009.01653.x

[22] Jansa, J., Mozafar, A., Anken, T., Ruh, R., Sanders, I. and Frossard, E. (2002) Diversity and Structure of AMF Communities as Affected by Tillage in a Temperate Soil. Mycorrhiza, 12, 225-234. http://dx.doi.org/10.1007/s00572-002-0163-z 
[23] Gamper, H.A., Walker, C. and Schüssler, A. (2009) Diversispora celata sp. Nov: Molecular Ecology and Phylotaxonomy of an Inconspicuous Arbuscular Mycorrhizal Fungus. New Phytologist, 182, 495-506. http://dx.doi.org/10.1111/j.1469-8137.2008.02750.x

[24] Hoagland, D.R. and Arnon, D.J. (1950) The Water-Culture Method for Growing Plants without Soil. Circular, California Agricultural Experiment Station, 347, 32.

[25] Vierheilig, A.P., Coughlan, Wyss, U. and Piché, Y. (1998) Ink and Vinegar, a Simple Staining Technique for Arbuscular Mycorrhizal Fungi. Applied and Environmental Microbiology, 64, 5004-5007.

[26] McGonigle, T.P., Miller, M.H., Evans, D.G., Fairchild, G.L. and Swan, J.A. (1990) A New Method Which Gives an Objective Measure of Colonization of Roots by Vesicular-Arbuscular Mycorrhizal Fungi. New Phytologist, 115, 495501. http://dx.doi.org/10.1111/j.1469-8137.1990.tb00476.x

[27] Einsmann, J.C., Jones, R.H., Pu, M. and Mitchell, R.J. (1999) Nutrient Foraging Traits in Ten Co-Occurring Plant Species of Contrasting Life Forms. Journal of Ecology, 87, 609-619. http://dx.doi.org/10.1046/j.1365-2745.1999.00376.x

[28] Hodge, A. (2004) Plastic Plants and Patchy Soils. Journal of Experimental Botany, 57, 401-411. http://dx.doi.org/10.1093/jxb/eri280

[29] Wang, L., Mou, P.P. and Jones, R.H. (2006) Nutrient Foraging via Physiological and Morphological Plasticity in Three Plant Species. Canadian Journal of Forest Research, 36, 164-173. http://dx.doi.org/10.1139/x05-239

[30] Johnson, N.C., Graham, J.H. and Smith, F.A. (1997) Functioning of Mycorrhizal Associations along the MutualismParasitism Continuum. New Phytologist, 135, 575-585. http://dx.doi.org/10.1046/j.1469-8137.1997.00729.x

[31] Zhang, Y., Zhou, Z., Ma, X. and Jin, G. (2010) Foraging Ability and Growth Performance of Four Subtropical Tree Species in Response to Heterogeneous Nutrient Environment. Journal of Forest Research, 15, 91-98. http://dx.doi.org/10.1007/s10310-009-0153-5

[32] Slade, A.J. and Hutchings, M.J. (1987) Clonal Integration and Plasticity in Foraging Behaviour in Glechoma hederacea. Journal of Ecology, 75, 1023-1036. http://dx.doi.org/10.2307/2260311

[33] Oborny, B. (1994) Growth Rules in Clonal Plants and Environmental Predictability-A Simulation Study. Journal of Ecology, 82, 341-351. http://dx.doi.org/10.2307/2261302

[34] Wijesinghe, D.K. and Hutchings, M.J. (1997) The Effects of Spatial Scale of Environmental Heterogeneity on the Growth of a Clonal Plant: An Experimental Study with Glechoma hederacea. Journal of Ecology, 85, 17-28. http://dx.doi.org/10.2307/2960624

[35] Ackerly, D. (1997) Allocation, Leaf Display, and Growth in Fluctuating Light Environments. In: Bazzaz, F.A. and Grace, J., Eds., Plant Resource Allocation, Academic Press, San Diego, 231-264.

[36] Hutchings, M.J. and John, E.A. (2004) The Effects of Environmental Heterogeneity on Root Growth and Root/Shoot Partitioning. Annals of Botany, 94, 1-8. http://dx.doi.org/10.1093/aob/mch111

[37] Verbruggen, E., Röling, W.F.M., Gamper, H.A., Kowalchuk, G.A., Verhoef, H.A. and van der Heijden, M.G.A. (2010) Positive Effects of Organic Farming on Below-Ground Mutualists: Large-Scale Comparison of Mycorrhizal Fungal Communities in Agricultural Soils. New Phytologist, 186, 968-979. http://dx.doi.org/10.1111/j.1469-8137.2010.03230.x

[38] Kiers, E.T. and van der Heijden, M.G.A. (2006) Mutualistic Stability in the Arbuscular Mycorrhizal Symbiosis: Exploring Hypotheses of Evolutionary Cooperation. Ecology, 87, 1627-1636. http://dx.doi.org/10.1890/0012-9658(2006)87[1627:MSITAM]2.0.CO;2

[39] Smith, F.A., Grace, E.J. and Smith, S.E. (2009) More Than a Carbon Economy: Nutrient Trade and Ecological Sustainability in Facultative Arbuscular Mycorrhizal Symbioses. New Phytologist, 182, 347-358. http://dx.doi.org/10.1111/j.1469-8137.2008.02753.x

[40] Collins, C.D. and Foster, B.L. (2009) Community-Level Consequences of Mycorrhizae Depend on Phosphorus Availability. Ecology, 90, 2567-2576. http://dx.doi.org/10.1890/08-1560.1 